\title{
Toxoplasma gondii in Australian smallgoods
}

\author{
Tatjana Momcilovic
}

From Parasite infections of domestic animals in the Nordic countries - emerging threats and challenges. The 22nd Symposium of the Nordic Committee for Veterinary Scientific Cooperation (NKVet) Helsinki, Finland. 7-9 September 2008

\section{Summary}

Toxoplasma gondii is one of the most common parasitic infections of humans and other warm-blooded animals. In most adults it does not cause serious illness, but severe disease may result from infection of fetuses and immuno-compromised people. Consumption of raw or undercooked meats has been consistently identified as an important source of exposure to T. gondii. Several studies indicate the potential failure to inactivate $T$. gondii in the processes of cured meat products, referred to as smallgoods in Australia.

This publication presents a qualitative risk-based assessment of the processing of ready-to-eat smallgoods. The raw meat ingredients are rated with respect to their likelihood of containing $T$. gondii cysts and an adjustment is made based on whether all the meat from a particular source is frozen. Next the effectiveness of common processing steps to inactivate $T$. gondii cysts are assessed, including addition of spices, nitrates, nitrites and salt, use of fermentation, smoking and heat treatment, and the time and temperature during maturation. It is concluded that processing steps which may be effective in the inactivation of $T$. gondii cysts include freezing, heat treatment and cooking, and the interaction between salt concentration, maturation time and temperature. The assessment is the illustrated using a Microsoft Excel based software tool which was developed to facilitate the easy assessment of four hypothetical smallgoods products.

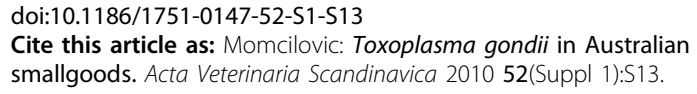

Norwegian School of Veterinary Science, P.O.Box 8146, 0030 Dep Oslo, Norway
Submit your next manuscript to BioMed Central and take full advantage of:

- Convenient online submission

- Thorough peer review

- No space constraints or color figure charges

- Immediate publication on acceptance

- Inclusion in PubMed, CAS, Scopus and Google Scholar

- Research which is freely available for redistribution 